\title{
THE MEDICAL MALPRACTICE CRISIS: A COMPARATIVE EMPIRICAL PERSPECTIVE
}

\author{
Donald N. Dewees*, Michael J. Trebilcock**, \\ and Peter C. Coyte***
}

\section{INTRODUCTION}

The 1980's have seen a crisis in medical malpractice liability in the United States, in Canada, and in the United Kingdom. ${ }^{1}$ This paper presents the results of a detailed empirical study of the Canadian malpractice experience. Our analysis has two important comparative reference points: First, it compares malpractice trends in Canada with trends in the United States, the United Kingdom, and Australia. Second, the paper compares the malpractice liability experience in Canada of physicians with the malpractice experience of dentists, engineers, lawyers, and chartered accountants, and with trends in personal injury claims for automobile accidents. This comparative approach allows us to suggest factors that have contributed to growth in claims frequency and severity in all three countries, and to reject some popular conceptions about the origins of the crisis. We analyze three sets of factors that are often associated with rising trends in frequency and severity of malpractice claims: changes in the professional environment, changes in the social environment, and changes in the legal environment. On the basis of our results, we believe that the first two sets of factors have attracted insufficient attention relative to the third in current research and policy analysis.

Copyright $@ 1991$ by Law and Contemporary Problems

Earlier versions of this article, which first introduced several of the tables included here, were published in 17 Melbourne U L Rev 539 (1990); 324 New Eng J Med 89 (January 10, 1991); and Peter H. Schuck, Tort Law and the Public Interest (Norton, 1991). This expanded version is printed with the permission of the publishers of each of these earlier works.

* Professor of Economics and Law, University of Toronto.

** Professor of Law and Economics, University of Toronto.

*** Associate Professor of Health Economics, University of Toronto.

We would like to thank participants in workshops at the University of Western Ontario and at Harvard University, particularly Alan Stone, Steven Shavell, and Lucien Bebchuck for comments on earlier drafts of this paper. We are also indebted to Randy Bovbjerg for comments.

1. See, for example, Patricia M. Danzon, The "Crisis" in Medical Malpractice: A Comparison of Trends in the United States, Canada, the United Kingdom and Australia, 18 L, Med \& Health Care 48 (1990); Frank A. Sloan \& Randall R. Bovbjerg, Medical Malpractice: Crises, Response, and Effects, Health Ins Ass'n Am Res Bull (May 1989). 
II

\section{The Dimensions of the "Crisis": Rising Trends in Frequency AND SEVERITY}

Following a period of minimal malpractice litigation in the 1940's and 1950's, claims filings and payments in Canada began to grow in the 1960's. Between 1971 and 1990, the average compound annual growth rate in claims filed per 100 physicians in Canada was 6.1 percent, implying that the claims frequency more than trebled over this period. (See Table 1.) Between 1971 and 1990, the number of claims paid per 100 physicians grew at an average compound annual growth rate of 4.9 percent, representing a 150 percent increase in the paid claim frequency rate over this period. In absolute terms, the average frequency of claims filed against physicians in the United States is about five times greater than in Canada. ${ }^{2}$ Between 1970 and 1985, however the growth rate in frequency of claims in the United States was quite similar ${ }^{3}$ to that in Canada although by 1988 the U.S. rate had fallen more sharply than that in Canada.

With respect to severity, the Canadian data indicate a five-fold increase in the average malpractice claim payment in real terms between 1971 and 1990 . (See Table 2.) Again, the increase in average payments in Canada and the United States in recent years is similar, with U.S. average payments doubling between 1980 and 1986.4 The absolute level of average payments in Canada has averaged about two-thirds that in the United States through the 1980's.

United Kingdom data on rates of growth in frequency and severity of malpractice claims over the past decade reflect rates of increase comparable to those experienced in Canada and the United States. (See Table 4.) United Kingdom frequency rates, on a population basis, appear to be significantly higher than Canadian rates. Danzon also reports, in relation to the Australian medical malpractice experience, that incidents notified to both of the main medical defence unions of New South Wales doubled between 1984 and 1986.5

With respect to insurance fees (levied in Canada by the Canadian Medical Protective Association), the overall compound annual rate of growth in these fees per physician, adjusted for inflation, between 1976 and 1990 is 12.6 percent. The bulk of this growth occurred between 1982 and 1988 when average fees tripled in real terms by 1986 and rose over 40 percent in 1987 , yielding an average annual compound growth rate of 32.4 percent. (See

2. In the United States, insurers typically establish a separate claim file for each defendant physician, while in Canada a single accident is covered by one claim, even when there are multiple physician defendants. There are on average 1.61 defendant physicians per claim in Canada; therefore, while the recent ratio of claims per physician in the United States has been more than eight times that in Canada, the ratio of injuries litigated is closer to five to one.

3. Danzon estimates a $10 \%$ annual growth rate in U.S. claims frequency between 1976 and 1984. Danzon, $18 \mathrm{~L}$, Med \& Health Care at 56, Table 1 (cited in note 1). Id.

4. Danzon reports a U.S. growth rate of real severity of $14 \%$ per year between 1980 and 1987.

5. Id at 51 . 
TABLE 1

Canada and the U.S.: Parallel Growth in Malpractice Frequency Claims Per 100 Physicians

\begin{tabular}{|c|c|c|c|c|c|}
\hline & \multicolumn{2}{|c|}{ Canada } & \multirow{2}{*}{$\begin{array}{c}\text { United States } \\
\text { Claims Filed** } \\
\text { (3) }\end{array}$} & \multirow{2}{*}{$\begin{array}{c}\text { Ratio } \\
(3) /(1) \\
(4)\end{array}$} & \multirow{2}{*}{$\begin{array}{c}\text { Canada } \\
\text { Writs Filed } \\
\text { Per Real } 1990 \\
\text { Billion \$'s Billed }\end{array}$} \\
\hline & $\begin{array}{l}\text { Writs Filed } \\
\text { (1) }\end{array}$ & $\begin{array}{c}\text { Claims Paid } \\
(2)\end{array}$ & & & \\
\hline $1940-60$ & 0.16 & $<0.10$ & $1.0(1960)$ & 6.3 & \\
\hline 1965 & 0.30 & 0.09 & & & \\
\hline 1970 & & & 4.5 & 8.2 & \\
\hline 1971 & 0.55 & 0.21 & & & \\
\hline 1972 & 0.60 & 0.22 & & & \\
\hline 1973 & 0.62 & 0.13 & & & \\
\hline 1974 & 0.77 & 0.23 & & & \\
\hline 1975 & 0.77 & 0.17 & 7.0 & 9.1 & \\
\hline 1976 & 0.76 & 0.23 & & & 100.6 \\
\hline 1977 & 0.85 & 0.22 & 7.5 & 8.8 & 113.1 \\
\hline 1978 & 1.00 & 0.25 & & & 130.5 \\
\hline 1979 & 1.03 & 0.33 & & & 132.7 \\
\hline 1980 & 1.31 & 0.38 & 10.6 & 8.1 & 165.3 \\
\hline 1981 & 1.42 & 0.39 & 11.4 & 8.0 & 179.1 \\
\hline 1982 & 1.38 & 0.41 & 13.3 & 9.6 & 172.8 \\
\hline 1983 & 1.55 & 0.53 & 15.1 & 9.7 & 196.2 \\
\hline 1984 & 1.60 & 0.32 & 16.5 & 10.3 & 201.2 \\
\hline 1985 & 2.13 & 0.36 & 17.8 & 8.4 & 277.8 \\
\hline 1986 & 1.84 & 0.46 & 17.0 & 9.2 & \\
\hline 1987 & 1.81 & 0.41 & & & \\
\hline 1988 & 1.70 & 0.39 & 13.0 & 7.6 & \\
\hline 1989 & 1.67 & 0.48 & & & \\
\hline 1990 & 1.70 & 0.52 & & & \\
\hline Growth rate*** & $6.1 \%$ & $4.9 \%$ & $6.1 \%$ & & \\
\hline
\end{tabular}

* The number of writs filed and claims paid is obtained from the CMPA. The number of physicians is the membership of the CMPA.

** These figures are derived from St. Paul Fire and Marine Insurance Company, the leading U.S. underwriter of malpractice insurance, by Danzon, Medical Malpractice at 60 (cited in note 10); Danzon, 49 L \& Contemp Probs at 63 (cited in note 9); U.S. Gen Acct'g Office, Medical Malpractice at Table 2.5 (cited in note 12); and Paul C. Weiler, Medical Malpractice on Trial at ch. 2 (cited in note 16). The 1970 figure is overstated by an unknown amount.

*** Compound annual average growth rate 1971-90 (1970-88 for U.S. claims).

Table 3.) Danzon reports that U.S. insurance premiums for basic limits grew at an annual rate exceeding 20 percent in nominal terms between 1976 and $1987,{ }^{6}$ but the real growth rate was closer to 7 percent, well below the Canadian growth rate. However, in 1987 Canadian dollars, average malpractice fees in the United States appear to have been over ten times higher than in Canada, reflecting principally the much higher litigation rate in the United States. Over the decade 1978-1988, United Kingdom defence society subscription rates increased by almost 40 percent a year in nominal terms. ${ }^{7}$

\footnotetext{
6. Id at 56, Table 1 .

7. See id at Table 4.
} 
TABLE 2

\section{Growth in the Average Value of Paid Claims Thousands of 1990 U.S. Dollars}

\author{
Canada* \\ Average Paid Claims
}

(1)

1970

1971

1972

1973

1974

1975

1976

1977

1978

1979

1980

1981

1982

1983

1984

1985

1986

1987

1988

1989

1990

25.7

16.9

25.7

34.4

42.9

80.9

66.7

27.4

81.2

41.3

51.8

47.7

61.9

112.4

98.0

82.1

115.0

119.1

135.3

145.7
United States**

Average Paid Claims

(2)
Ratio

(2)/(1)

(3)

37.1

61.9

1.44

58.8

0.73

71.9

1.08

86.8

3.17

51.5

1.25

68.5

1.32

80.5

1.69

89.2

1.44

101.4

0.90

103.6

1.06

110.2

1.34

Growth Rate***

$9.6 \%$

$11.2 \% 1970-78$

$13.5 \% 1980-86$

* Average paid claims are obtained from Dewees, Coyte and Trebilcock, Canadian Medical Malpractice Liability at Table 2-4 (cited in note 8). These paid claims are converted to 1990 U.S. dollars with use of the Canadian Consumer Price Index, derived from the Bank of Canada Review, various issues, and the 1990 exchange rate of $\$ 1.00$ (U.S.) to $\$ 1.167$ (Canadian).

** The U.S. Consumer Price Index was used to convert the U.S. dollars in each year to 1990 U.S. dollars. These data are from Danzon, Medical Malpractice at 151 (cited in note 10); Nat'l Ass'n Ins. Commissioners (1980), Medical Malpractice Closed Claims 1975-78 (NAIC, 1975-1978); Sloan \& Bovbjerg, Health Ins Ass'n Am Res Bull at 7 (1980-86) (cited in note 1). The data for the 1970 's and the 1980's are from different sources and are not necessarily consistent, so direct comparison cannot be made between the two.

*** Compound average annual growth rate 1971-90 (Canada).

In summary, Canada, the United States and some Commonwealth countries have experienced considerable growth in the frequency and severity of malpractice claims in the 1970's and 1980's. Both have grown in spurts, but the long term average has exceeded 6 percent per year. Malpractice insurance premiums have grown even more rapidly and more irregularly. Claims frequency in the United States is five times that in Canada, severity is one-third greater, and insurance fees are about ten times greater. 
TABLE 3

Average Per Physician Malpractice Premiums 1990 U.S. Dollars

Canada*

(1)

1974

1975

1976

1977

1978

1979

1980

1981

1982

1983

1984

1985

1986

1987

1988

1989

1990

Growth rate***

1976-90

1982-88

399

443

405

365

437

384

504

794

1013

1261

1793

2064

2077

2101

$12.6 \%$

$32.4 \%$
United States * *

6,350

10,322
Ratio

(2)/(1)

(3)

25.9
19.6

17.2

12.8

12.1

11.5

9.2

8.2

* Total CMPA fee revenues divided by the number of members. These fees are converted to 1990 U.S. dollars with use of the Canadian Consumer Price Index, derived from the Bank of Canada Review, various issues, and the 1990 exchange rate of $\$ 1.00$ (U.S.) to $\$ 1.167$ (Canadian).

** The average malpractice premiums for the U.S. were reported by Roger A. Reynolds, John A. Rizzo \& Martin Gonzalez, $257 \mathrm{~J}$ Am Med Ass'n 2776 (cited in note 16), and Department of Health and Human Services, 1987. Report of the Task Force on Medical Liability and Malpractice. (Washington, D.C.: US GPO, 1987). These figures were derived from the American Medical Association's Periodic Survey of Physicians and Socioeconomic Monitoring System Survey. The 1988 figure is from the same survey but presently unpublished. The U.S. consumer price index was used in each year to convert to 1990 U.S. dollars.

*** Compound average annual growth rate.

\section{III}

\section{The Canadian Malpractice and Liability Data}

For our study, we assembled several data sets that have never been analyzed for these purposes before in Canada. Physician liability data for the years 1976 to 1987 were provided by the Canadian Medical Protective Association ("CMPA"). The CMPA is a non-profit organization of which over 90 percent of all active civilian physicians in Canada are members. Malpractice claims against almost all physicians in Canada are defended by the CMPA. The CMPA data include information on the type of injury alleged, the specialty of the physicians named, patient age, gender and place of residence, and other information about the patient, the physicians, the event, and the progress of the claim to dismissal, settlement or trial. We refer to 
TABLE 4

Similar InCreases in Malpractice Litigation in the U.K.

\begin{tabular}{lcccc} 
Year & $\begin{array}{c}\text { Claims Opened } \\
\text { Region E }\end{array}$ & $\begin{array}{c}\text { Average } \\
\text { Award*** } \\
(1976=100)\end{array}$ & $\begin{array}{c}\text { Maximum } \\
\text { Award*** } \\
(£ \text { 000) }\end{array}$ & $\begin{array}{c}\text { Defence Society } \\
\text { Rates**** } \\
(£)\end{array}$ \\
1976 & & 100 & & \\
1977 & & 110 & 133 & \\
1978 & 4.0 & 140 & 229 & 40 \\
1979 & 4.1 & 105 & 220 & 70 \\
1980 & 4.2 & 200 & 263 & 95 \\
1981 & 5.1 & 230 & 312 & 120 \\
1982 & 5.3 & 360 & 399 & 135 \\
1983 & 7.5 & 280 & & 195 \\
1984 & 9.3 & 370 & & 264 \\
1985 & 12.3 & 420 & 414 & 288 \\
1986 & 16.5 & & 581 & 336 \\
1987 & 20.4 & & 679 & 576 \\
1988 & 19.6 & & 1030 & 1080 \\
Growth Rate & $17.2 \%$ & $17.3 \%$ & $20.0 \%$ & $39 \%$ \\
\hline All & & & & \\
\hline
\end{tabular}

All data from Ham, Dingwall, Fenn, Harris, Medical Negligence (cited in note 34). All financial data are in nominal pounds; that is, there is no correction for inflation in these figures.

* Ham, et al, at Fig. 5. Claim rate for region $E$ in England, which is the region with the highest claims rate.

** Ham, et al, at Fig. 2. Average cost of settlements from the Medical Protective Society.

*** Ham, et al, at Fig. 3. Highest sum awarded in medical negligence cases, as reported by the Medical Defense Union.

**** Ham, et al, at Table 3. Full subscription rates paid to the medical defense societies. These rates appear to be common to the Medical Defense Union and the Medical Protective Society.

data from the CMPA closed and open claims file throughout this paper as the semi-aggregate data set. In this data set, the CMPA identified all paid claims over the period 1976-1987 in which payment to the plaintiff exceeded $\$ 100,000$ in 1976 Canadian dollars and provided us with an additional body of detailed data on these claims. One hundred and seven such claims were identified accounting for just over one half of total payments between 1976 and 1987: $\$ 56$ million out of $\$ 106$ million, Data gathered from hospital insurers confirm the significance of a small number of large claims in determining total losses: 4.27 percent of all claims filed against Canadian hospitals between 1977 and 1983 accounted for two-thirds of all incurred losses during this period. These data form the basis for our statistical analysis of the determinants of malpractice litigation in Canada.

We also gathered information from hospital insurers regarding the claims experience of hospitals across Canada. Because no single company insures all hospitals, the hospital liability data are much less complete and consistent than those for physicians. We also conducted a survey of hospital administrators to determine both their claims experience and their response to claims that were made. These data were used to test the conclusions drawn from the CMPA data set.

Each province's health insurance plan generates data on the amount billed for all types of medical services. We have used summaries of these data, after 
adjusting for changing physician fee levels over time, as measures of the activity level of physicians in our attempt to explain liability trends.

We surveyed the provincial colleges of physicians and surgeons for data on the types of matters that attracted the attention of the self-regulating disciplining processes of the medical profession, and about the level of activity of that process. The results of this survey have been used to evaluate the current and potential role of discipline bodies in the control of the quality of health care.

To test the hypothesis that the trends in health care liability are unique, we gathered data on the liability experience of other professionals: dentists, lawyers, accountants, architects, and engineers. These data were gathered either from the professional bodies themselves or from major insurers of those practitioners.

We also gathered data on the frequency and severity of third-party bodily injury claims arising out of automobile accidents from the Insurance Bureau of Canada which compiles comprehensive data from insurers in several provinces. These data provide a trend against which the medical liability trends may be compared. Unlike many areas of professional liability not involving personal injury, automobile personal injury trends might be expected to move more closely in line with medical malpractice claims. Doctrines relating to the quantum of damages should be similar, although doctrines on liability itself may be quite different. If part of the increase in medical claims is due to general legal factors or to changes in general social attitudes towards litigation, this should be reflected in the automobile claims as well.

As indicated above, we used these hypotheses and data sets to investigate three classes of factors that might explain increasing trends in the frequency and severity of medical malpractice claims: changes in the professional environment, changes in the social environment, and changes in the legal environment. A significant portion of our investigation involved using multiple regression analysis on aggregated sets of the claims data. ${ }^{8}$ In the remainder of this paper we report some of the results most relevant for explaining the factors that have influenced malpractice litigation in Canada during the past two decades.

\section{IV}

\section{The Professional Environment}

This section discusses five types of medical trends that may have affected the frequency and the severity of malpractice claims: (a) increases or shifts in utilization of health care services; (b) changes in the quality of health care

8. The technical aspects of this regression analysis are presented elsewhere. See Donald $\mathrm{N}$. Dewees, Peter C. Coyte \& Michael J. Trebilcock, Canadian Medical Malpractice Liability: An Empinical Analysis of Recent Trends, in J. R. S. Prichard, ed, 1 Scope and Trends in Health Care Liability in Canada App B (U Toronto Press, 1990) (report to the Conference of Deputy Ministers of Health of the Federal/Provincial/Territorial Review on Liability and Compensation Issues in Health Care). 
professionals and/or institutions; (c) changes in modes of practice and degree of specialization; (d) complexity of medical procedures; and (e) the extent of professional disciplinary activities.

\section{A. Utilization of Health Care Services}

The frequency of malpractice claims and the total value of malpractice payments are expected to be positively related to the utilization of health care services. Thus we examined the impact of increased utilization in general on malpractice liability. However, we also wanted to test if increased utilization of specific procedures were positively related to increased malpractice liability. Although increased utilization in general may be associated with an increase in iatrogenic injuries, some procedures, such as major surgery, may be more prone to adverse outcomes than others. Conversely, some procedures, such as laboratory tests and diagnostic radiology, which clarify more precisely the patient's illness and the appropriate course of treatment, may reduce the patient's exposure to an iatrogenic injury. In some cases these procedures which may reduce the physician's rise of liability may be referred to as "defensive medicine." Consequently, we considered the effect on claims frequency of more specific procedures, such as major surgery, laboratory tests and diagnostic radiology. We expect increased laboratory tests and diagnostic radiology to lead to reduced claims frequency. We also examined the impact of several specific medical procedures on the severity of malpractice awards. Since some activities, such as surgical procedures, may have more obvious adverse outcomes than other procedures and since they may also result in more serious medical misadventures, we expect these procedures to be positively correlated with the frequency and severity of malpractice claims.

1. General Utilization. Consider first the general increase in the frequency of claims filed over time. There was a seven-fold increase in the absolute number of claims filed in Canada between 1971 and 1988 (from 130 in 1971 to 873 in 1988)-an estimated 11.9 percent per year increase. To what extent might this increase be attributable to growth in the number of physicians, in the total amount of medical service performed or in the amount of major surgical services performed? Several U.S. studies have found that increases in the number of surgical procedures per capita $^{9}$ or physicians per capita ${ }^{10}$

9. Patricia M. Danzon, The Frequency and Severity of Medical Malpractice Claims: New Evidence, 49 L \& Contemp Probs 57, 70 (Spring 1986); Stephen Zuckerman, Randall R. Bovbjerg \& Frank A. Sloan, Effects of Tort Reform and Other Factors on Medical Malpractice Insurance Premiums, 27 Inquiry 167, 180 (1990).

10. Patricia M. Danzon, The Frequency and Severity of Medical Malpractice Claims, 27 J L \& Econ 115. 130 (1984); Patricia M. Danzon, Medical Malpractice: Theory, Evidence and Public Policy 72 (Harvard U Press, 1985); Frank A. Sloan, State Responses to the Malpractice Insurance Crisis of the 1970s: An Empirical Assessment, $9 \mathrm{~J}$ Health Pol, Pol'y \& L 629, 631 (1985); Frank A. Sloan, Paula M. Mergenhagen \& Randall R. Bovbjerg, Effects of Tort Reforms on the Value of Closed Medical Malpractice Claims: A Microanalysis, 14 J Health Pol, Pol'y \& L 663 (1989); Zuckerman, Bovbjerg \& Sloan, 27 Inquiry at 180 (cited in note 9). 
significantly increase the frequency of malpractice litigation. The Canadian data are more comprehensive, with access to the entire physician population, and billing data on all services performed including laboratory services. Dividing the frequency by the number of physicians (CMPA members) reduces the growth in frequency to a quadrupling, or 8.2 percent per year. The total value of medical services performed (from physician billing data, adjusted for inflation, see Table 1) grew only slightly more rapidly than the number of physicians, and explains the growth in frequency only slightly better. Major surgery actually grew less rapidly than total medical services, so it has no explanatory power for the increase in frequency once the number of physicians or the total value of medical services is considered. We conclude that the utilization of medical services is a major factor explaining the frequency of malpractice litigation, but that in Canada the number of physicians and the volume of medical treatment are roughly equal in their explanatory power. The role of major surgery is explored in more detail below.

With respect to hospital liability, our analysis suggests that admissions are a somewhat better measure of utilization than are beds for predicting claims frequency, and that a 10 percent increase in utilization leads to a 5 percent increase in the number of claims filed.

2. Specialization. Total malpractice claim costs equal the product of the frequency of malpractice claims, the success rate of those claims, and the average severity of paid claims. The proportion of total payments by the CMPA attributable to each specialty are shown in the last line of Table 5. Since the proportion of total payments attributable to anesthetists, orthopedic surgeons and obstetricians and gynecologists exceeds their proportion in the stock of physicians, these specialties are over-represented in the total payments by the CMPA. Orthopedic surgeons are over-represented by a factor of 4.8 , anesthetists by 3.2 , and obstetricians and gynecologists by 2.3 . In contrast, family practice is under-represented by one third. In order to explain these differences, we examined more closely the components of total malpractice claim cost: frequency and severity.

Table 5 presents the average claims frequency by specialty for the years 1976-1984. The average for orthopedic surgeons is twice that of obstetricians and gynecologists, four times that of anesthetists, and over 10 times that of family practitioners. Statistical analysis on these data confirmed that the differences in claims frequency among the physician categories shown in Table 5 are statistically significant." "We found that most of the variation in frequency across specialties can be explained by variations in the performance of major surgery (measured by billings) in each specialty. Indeed, utilization of major surgery explains fully 90 percent of the variation among years and among specialties in the frequency of claims filings, most of which represents

11. See also Danzon, Medical Malpractice at 72 (cited in note 10); Zuckerman, Bovbjerg \& Sloan, 27 Inquiry at 177 (cited in note 9). 


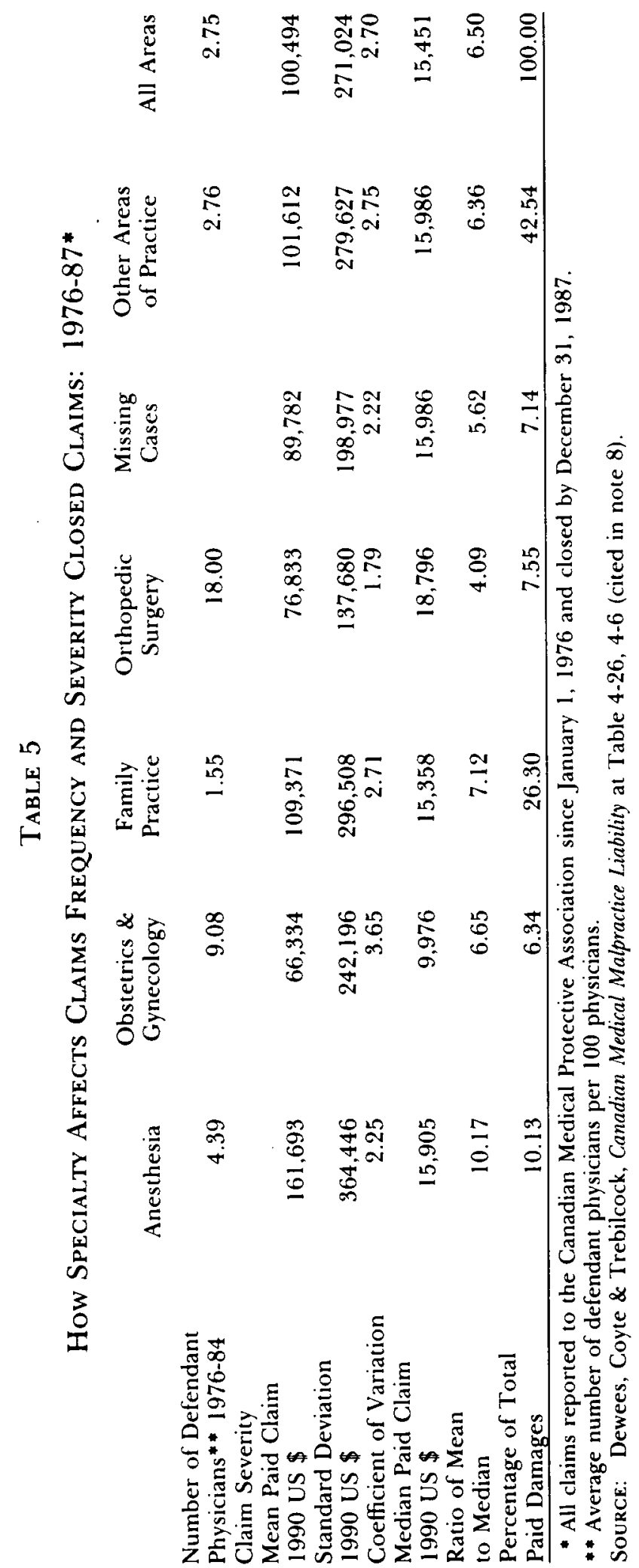


variation across specialties. Since most of the variation in frequency occurs among specialties, rather than over time, this 90 percent explanatory power for major surgery does not mean that most of the growth in frequency is explained by growth in surgery. Indeed, while the performance of major surgery accounts for most of the inter-specialty variation in frequency, the growth in frequency is better explained by the number of physicians or the total volume of medical service performed than by the growth in major surgery.

We also tested whether the severity or amount paid per claim differs significantly among areas of practice. The severity of malpractice claims, measured in 1987 dollars, is reported in Table 5. The mean (average) paid claim for all cases closed between 1976 and 1987 was $\$ 102,450$. There appears to be considerable variation across the six specialties; the mean paid claim involving anesthetists is over 60 percent greater than that for all CMPA members, while obstetricians and gynecologists record a mean severity that is 34 percent less than that for all CMPA members. However, if we focus on the median instead of the mean, as is appropriate for a skewed distribution such as this, we find that the differences in median severity among the six physician categories identified in Table 5 are not statistically significant. In other words, the differences in severity among the specialties in our data set are sufficiently small that we cannot be confident that the underlying severity is actually different for all specialties. Regression analysis confirmed our conclusion except that it found that severity of paid claims for anesthetists was significantly above that of the category of "all other areas of practice." This is in sharp contrast to the United States experience where large differences in size of average payment by specialty have been reported. ${ }^{12}$

This analysis does not explain conclusively why severity does not differ significantly among specialties, but some rationales may be offered. First, our data combine gynecology and obstetrics, so that the smaller expected frequency and severity of the former will produce a lower average severity than if obstetrics, which has generated very high premiums in the United States, could be isolated. Second, as we report above, the performance of major surgery explains most of the difference in claim frequency among specialties. We believe that this is consistent with a large portion of the losses being associated with the intrusive activities of the operating room, no matter which specialty performs the activities, simply because it is in the nature of these activities that if an error occurs, the potential loss is large, and a claim is likely to be filed. Since all specialties perform some of these activities leading to large losses, all experience similar severity. The smaller injuries caused by other activities lead to fewer claims being filed in those areas. Third, in the Canadian legal system, costs follow the event, which means that it is not profitable to pursue claims with a small likelihood of success, in contrast to the rule in the United States in which the plaintiff is rarely liable for the

12. See US Gen Acct'g Office, Medical Malpractice: Characteristics of Claims Closed in 1984, at 56, Table 4.4 (April 1987). 
defendant's costs. The lesser prevalence of contingent fees in Canada (Ontario still does not permit this arrangement formally) reduces the incentive for a plaintiff to file small claims. Furthermore, the CMPA's reputation for defending a claim that it does not believe is meritorious, regardless of size, requires the plaintiff to be prepared to risk high legal costs unless his case is so strong that the CMPA is prepared to settle early. In short, in Canada, there is a narrower range of claims that a plaintiff will feel that it is economically worthwhile to pursue, so the size of the payments varies less by specialty than in the United States.

Thus in sum we conclude that total malpractice payments per physician differ significantly by area of practice, with orthopedic surgeons, anesthetists, obstetricians and gynecologists giving rise to significantly above-average payments, while family practitioners give rise to significantly below-average payments. This arises from frequency rates that differ greatly, while success rates (not reported here) ${ }^{13}$ and median awards are similar for all specialties.

3. Treatments Giving Rise to Large Claims. Our analysis of specialties indicates that increased utilization of certain treatments such as surgery is positively correlated with increased medical malpractice costs. We thus proceeded to investigate the impact of certain treatments on medical malpractice costs. The large paid claims data (claims in excess of $\$ 100,000$ (1976 Canadian dollars) include a specification of the treatment being performed when the accident occurred. We analyzed the frequency with which various treatments are listed as associated with a claim, and the total amount paid in respect of each treatment, dividing the amount paid equally among the treatments in the many cases where more than one treatment was mentioned. With 54 mentions, "major surgery" represents 35 percent of the 155 treatments mentioned in these 107 cases. It is the first treatment mentioned in 40 percent of all claims, and accounts for 37 percent of all amounts paid. Obstetrics represents 11 percent of all treatments mentioned; it is the first treatment mentioned in 10 percent of all claims, and accounts for 14 percent of all amounts paid. This implies that obstetrics has the highest severity. ${ }^{14}$ We tested for trends in these data by comparing the earlier half of our data (pre-1985) with the latter half (post-1984). This yields 65 mentions of treatments in the early claims, and 90 mentions in the late claims. The proportion of mentions of "major surgery" decreased from 40 percent to 31 percent from the early to the late claims. The largest increases occur for obstetrics ( 8 percent to 13 percent), anaesthesia (5 percent to 10 percent), and radiology ( 1.5 percent to 4.4 percent). While these numbers are not statistically significant, particularly the small numbers of radiology claims,

13. See Dewees, Coyte \& Trebilcock, Canadian Medical Malpractice Liability at Table 4-15 (cited in note 8).

14. Since obstetrics accounted for $14 \%$ of all amounts paid and only $11 \%$ of the number of treatments mentioned, the average severity for obstetrics was $(14-11) / 11=27 \%$ above the average for all treatments. This was the highest ratio for any treatment. Id at ch $4, \mathrm{p} 14$. 
they are consistent with the hypothesis that injuries arising from obstetrical care and anaesthesia are a factor in the increase in total liability.

We also examined the sub-categories of treatments. Again, there are no surprises. The largest sub-category of "major surgery" is "musculo-skeletal: other," and the second largest subcategory is "musculo-skeletal: fractures." The largest sub-categories in the obstetrics category simply indicate "services at the time of confinement," and "confinement." These data are not sufficiently specific to test the often-stated hypothesis that injuries to infants who would not in the past have survived now cause enormous settlements and are an important force driving the increase in liability. We have, however, identified those cases involving injury to infants at childbirth. There are 10 such claims, representing 9 percent of our large claims data set, with total damages paid of $\$ 9.6$ million in 1987 dollars, or 15 percent of the large claims total: This confirms that serious injuries to infants during childbirth give rise to higher than average damages, and that the total magnitude of these claims is substantial. Furthermore, 6 of these 10 claims, representing $\$ 6.8$ million were paid with the "late" claims, weakly suggesting an increase in the relative importance of this particular category of claim over the period of analysis.

The large claims data also list the allegations of malpractice that gave rise to the claim. One-quarter of the allegations (39) mentioned "treatment," accounting for 19 percent of the damages. The most common treatment errors were "delay in treatment," "improper choice of treatment," and "other." Eighteen percent of the allegations (33) mentioned "anaesthesia," and the expectation that anesthesia errors would cause high cost injuries is confirmed by the large implicit average severity, since these claims account for 31 percent of the damages. The most common anesthesia errors were "failure to monitor," "improper administration," "improper intubation," and "other." Surgery accounted for 18 percent of the allegations (28) but only 12 percent of the damages, revealing a lower than average severity for these accidents. The most common error listed is simply "improper performance." "Diagnosis" accounted for 17 percent of the allegations and 15 percent of the damages. Most of these errors are attributed to "failure to diagnose" or to "misdiagnosis."

We compared the distribution of allegations of malpractice between early and late claims. This revealed a decline ( 17 to 10$)$ in allegations related to diagnosis and to monitoring ( 5 to 1 ), and increases in most other categories, particularly obstetrics (3 to 8). Again, small numbers preclude drawing robust conclusions, nor do they suggest important causes of trends in overall malpractice litigation.

This analysis of treatments involved in large claims confirms our conclusion that major surgery is a primary determinant of claims frequency. It also indicates that obstetrics leads to larger than average claims, particularly when the claim involves injury to the newborn. The aggregate data set may not be inconsistent with this result, since it reports on obstetrics and gynecology together, and average claims for the latter are likely to be much 
smaller than those for the former. The analysis also shows that anesthesia is associated with above average severity, which again may be consistent with the aggregate data which show a median claim for anaesthesia that is similar to the other specialties but a mean claim that is the highest of the group, indicating a small number of large claims.

4. Defensive Medicine. In 1984 the AMA asked physicians to report changes in their practice patterns in response to the threat of civil liability. Forty-one percent reported ordering extra tests, 36 percent spending more time with patients, 57 percent keep more detailed records, 45 percent refer more cases. ${ }^{15}$ While all these responses may be termed defensive medicine, ${ }^{16}$ they do not necessarily fail to benefit patients as is often implied; indeed they may often be beneficial to patients. Some activities may actually reduce the patient's exposure to an iatrogenic injury, such as procedures that clarify more precisely the patient's illness and the appropriate course of treatment, such as those associated with laboratory tests and diagnostic radiology. Defensive medicine, defined more narrowly however, might be taken to refer only to procedures induced by the threat of liability that have little or no therapeutic value. No studies to date of defensive medicine have attempted to segregate out such procedures. ${ }^{17}$ In our study, we examine increases in radiological services and laboratory tests, but do not attempt to quantify the purely defensive elements in these procedures. To test whether these procedures were important in explaining the trends in malpractice liability, we included the total cost of these procedures per physician, adjusted for increases in the fee-benefit schedule, in each of the regression equations. The coefficient of this cost variable was insignificant in each case, indicating that our measure of 'defensive medicine' fails to reduce the frequency of claims filed, the proportion of claims that succeed, and the average magnitude of an award.

\section{B. Quality of Health Care Professionals and Their Institutions}

Health care professionals may differ in the quality of care offered to their patients because of differences in professional expertise. Such differences might be due to their medical training, age and experience, or location of practice. While high quality should lead to fewer adverse outcomes, high quality providers may attract the most difficult cases, rendering any interpretation of a relationship between a quality measure and outcomes ambiguous. To capture the effect of quality on the litigation process, three

15. Patricia M. Danzon, Medical Malpractice: An Overview of the Issues 10 (presented at a workshop on law and economics, University of Toronto, March 18, 1987).

16. A recent estimate of the cost of defensive medicine in the United States puts the figure at between $\$ 9-10$ billion in 1984 (compared to $\$ 3$ billion paid by physicians for malpractice premiums in that year), while other U.S. estimates range from $\$ 15-\$ 40$ billion per year. Roger A. Reynolds, John A. Rizzo \& Martin L. Gonzalez, The Cost of Medical Professional Liability, 257 J Am Med Ass'n 2776 , 2781 (1987); Paul C. Weiler, Medical Malpractice on Trial 85 (Harvard U Press, 1991).

17. Weiler, Medical Malpractice on Trial at 87-88 (cited in note 16). 
proxies for quality were employed: the physician's age; place of training; and location of practice.

Our statistical analysis of the semi-aggregate Canadian claims data indicated that domestically-trained physicians are less likely than foreigntrained physicians to be sued and that their losses will be smaller. However, the large claims data (claims in excess of $\$ 100,000$ in 1976 Canadian dollars) did not show any significant difference in frequency or severity for domestically-trained and foreign-trained physicians. Nor do we find support in the large claims data for the hypothesis that malpractice is more common among newly graduated physicians or among older physicians, since we found that the age distribution of physicians named in successful large claims did not contain a disproportionate number of young or old physicians.

We have only a weak test for recidivism, but our test suggests that recidivism is not an important factor in generating the large claims. Of 107 large claims, only three involved physicians with the same birth year, place of training, and city of practice, and these may not have been the same individual.

Finally, the large claims data reveal that large claims arise more often in large cities relative to the size of the place of residence of the patient. In other words, there is either a migration of difficult cases from smaller places to larger places for treatment or, less likely, there is a higher rate of malpractice in larger centers. These results seem broadly consistent with U.S. data. ${ }^{18}$

We conclude that foreign-trained physicians may experience a modestly greater likelihood of being sued than domestically-trained physicians, and their losses may be somewhat greater. We failed to find an association between frequency of claims and the age of the physician; and a weak test for recidivism was negative. Finally it appears that there is some migration of cases likely to lead to litigation from smaller cities to larger cities.

\section{Mode of Practice, Degree of Specialization}

The mode of practice may affect both the frequency and severity of malpractice claims in several ways. One distinction is between the generalist and the specialist. Presumably the specialist offers higher quality care, but is held to a higher standard of care. More confusingly, the specialist may deal with the majority of the difficult cases in which adverse outcomes are more likely. Studying litigation rates for specialists and generalists should indicate which of these effects dominate.

In our study, we defined a specialist as a physician in an area of practice other than family practice. Using this definition we find that an increase in specialization is negatively associated with both the proportion of paid claims and the severity of claims, while specialization is positively associated with the frequency of malpractice claims. However, none of these results is statistically

18. See, for example, Frank A. Sloan, et al, Medical Malpractice of Physicians: Predictable or Haphazard?, $262 \mathrm{~J}$ Am Med Ass'n 3291 (1989). 
significant in any of the estimated regression equations. Consequently, the effects of specialization on malpractice litigation, as identified above, appear to just offset each other such that changes over time in the degree of specialization do not significantly affect malpractice litigation. ${ }^{19}$

Another distinction is between a solo practitioner and one in a group practice. In the latter case there may be superior internal quality control checks, on the one hand, but a diminished sense of responsibility on the part of individual physicians for the outcome of treatment, on the other. ${ }^{20}$ Unfortunately, the actual arrangements between practitioners in Canada are sufficiently varied that considerable errors of interpretation would arise in trying to measure the proportion of solo or group practitioners in Canada, so we have conducted no test of this relationship. ${ }^{21}$

Other changes in modes of medical practice have probably facilitated malpractice litigation as well. We were told that in the past the "conspiracy of silence" often led physicians to refuse to testify for malpractice plaintiffs as to the appropriateness of the defendant's conduct, but this reticence has substantially eroded in Canada over the past two decades, greatly improving the ability of plaintiffs to pursue meritorious claims. Nurses, too, are more willing now than in the past to testify as to events that take place in hospitals. Finally, the increasing complexity of medical care and the increased number of treatments offered to seriously injured patients means that more physicians and other staff are likely to be involved with a given patient, so that errors made by one physician are now more likely to be observed than in the past, at least for accidents occurring in hospitals. While our data do not allow us to perform direct tests of these hypotheses, we believe that they are plausible contributors to some of the unexplained growth during the study period.

\section{Complexity of Medical Procedures}

To the extent that the data suggest a greater increase in the propensity to litigate claims against physicians or hospitals than in other professional contexts (discussed below), the conundrum that requires explanation is that with rapid rates of innovation in the provision of medical care, which presumably have reduced health-related risks to society, we have simultaneously witnessed a dramatic increase in the frequency of malpractice claims.

19. This does not contradict our finding, in Part IVA(2), that some specialties experience much greater litigation rates at all times than others.

20. Tests conducted in the United States indicate that physicians in groups experience more claims than solo practitioners. Kathryn M. Langwell \& Jack L. Werner, Regional Variation in the Determinants of Professional Liability Claims, 5 J Hcalth Pol, Pol'y \& L 498, 507-08 (1980); E. Kathleen Adams \& Stephen Zuckerman, Variations in the Growth and Incidence of Medical Malpractice Claims, $9 \mathrm{~J}$ Health Pol, Pol'y \& L 475, 485 (1984). Thus, group practice may not only be picking up the effect of this mode of practice on quality, but it may also be capturing the effect of social distance. Since many patients in groups are not attached to specific physicians, they may file a malpractice claim with less hesitation than patients who have built up a strong patient-physician relationship.

21. Sloan, et al, $262 \mathrm{~J}$ Am Med Ass'n at 3295 (cited in note 18), find no significant correlation between solo practice and frequency of malpractice claims. 
Grady has recently hypothesized that in periods of rapid technological innovation, which may indeed be reducing health risks for society at large, the possibilities for momentary acts of inadvertence by physicians and other medical staff are sharply increased and that negligence law is insensitive to the costs entailed in achieving consistently higher levels of advertence. ${ }^{22} \mathrm{He}$ argues, for example, that prior to the invention of dialysis machines, patients frequently died from kidney failure, but these natural events fell outside the purview of the tort system. Following the invention of dialysis machines, which sharply reduced mortality rates from kidney failure, the possibilities of inadvertence by physicians and other medical staff in initial diagnosis as to the appropriateness of prescribing this form of medical intervention and in monitoring its application to particular patients thereafter, sharply increased. Similar theses might be advanced with respect to technically complex forms of surgery, such as brain surgery or open heart surgery, or technically complex interventions in the case of premature babies, where the possibilities of momentary acts of inadvertence, with the potential for serious outcomes, have been significantly multiplied. The Grady hypothesis can be loosely tested by examining differences in frequency of claims rates across specialties and by examining the nature of the medical procedures involved in malpractice claims.

There is another mechanism different from the Grady hypothesis, by which technological progress in medical practice might lead to increased litigation. Suppose that a certain procedure yields adverse outcomes for natural reasons (no negligence) in ten out of one hundred cases, and that in one out of one hundred cases there is an adverse outcome attributable to negligence. Suppose further that one can identify the case involving negligence only by a complete trial, which is costly. If injured patients sued for every adverse outcome, they would win only one out of 11 suits (9 percent). Given the high cost of litigation, especially under the Ontario cost and fee rules which prohibit contingent fees and require the loser to bear a large fraction of the winner's legal costs, bringing a claim on these facts would not be rational. However, assume that over time technological progress reduces the rate of adverse outcomes for natural reasons to one in one thousand, while the failure rate resulting from negligence is unchanged at one in one hundred. Now, an injured victim has a 91 percent chance of winning a suit, and may find that litigation is profitable. Thus, medical developments that reduce the rate of natural injuries may cause malpractice litigation to arise where none existed before, driven by the radically changed economics of litigating the cases. This hypothesis would yield increases in malpractice litigation coincident with improving medical technology, but without assuming that the new technology requires improved vigilance by physicians.

22. See generally Mark F. Grady, Why are People Negligent? Technology, Nondurable Precautions, and the Medical Malpractice Explosion, 82 NW U L Rev 293 (1988). See also Stephen Shavell, Economic Analysis of Accident Law 81 (Harvard U Press, 1987); Peter A. Diamond, Single Activity Accidents, $3 \mathrm{~J}$ Legal Stud 107 (1974). 
A third distinct explanation assumes that over time a given patient problem has received an increasing number of treatments. Each additional treatment reduces the overall chance of an adverse outcome, but may give rise to a lawsuit if the outcome is adverse and the physician cannot prove that it has been performed correctly. Assume that there is some probability that even a correctly performed procedure cannot in fact be proven to be performed correctly and that in some such cases the jury will find for the plaintiff. Once again, even though additional procedures improve patient outcomes, the number of successful lawsuits may rise. ${ }^{23}$

These examples represent only three of a number of models in which progress in medical treatment that improves patient outcomes on average may nevertheless lead to increasing rates of successful malpractice claims. The models are driven by: more demanding technology, the reduction of non-negligent outcomes and imperfect information about the occurrence of negligent acts.

In our study we were able to obtain details of the nature of the treatment and the allegations of malpractice only for the 107 large claims, and a review of these data does not reveal large numbers of errors that appear to involve recent and demanding technology. Moreover, it is often difficult to determine whether a report that a procedure was improperly performed is an example of momentary inadvertence. However, the prevalence of major surgery (37 percent of losses) among the treatments giving rise to injuries and of anaesthesia (32 percent of losses) among the allegations of malpractice, indicate the importance of these highly intrusive activities in generating large claims. If it is fair to characterize major surgery as an activity in which a momentary lapse in attention or judgment raises risks of serious injury, then the Grady hypothesis is also supported by our finding above that much of the variation in claims frequency across specialties is explained by variations in the performance of major surgery. Among the anaesthesia claims were many alleging failure to monitor the patient's condition, which is consistent with momentary inadvertence while using technology that is life-threatening. The errors in diagnosis ( 15 percent of losses) might represent momentary inadvertence in cases where proper diagnosis could have led to an intervention of great efficacy. A number of other claims mention failure to monitor drug doses, or to diagnose certain patient conditions, but again it is difficult to determine whether these lapses represent momentary inadvertence. We were told by lawyers on both sides of the Canadian malpractice litigation bar that most of the claims do not arise from the general incompetence of a physician, but from a momentary lapse by a competent practitioner. This view is supported by our inability to find evidence of recidivism in the large claims data.

Thus, while our data do not allow us to prove the Grady hypothesis, they are clearly not inconsistent with it, particularly if one interprets it as referring

23. This example was suggested to us by Alan Stone and Steven Shavell, both of Harvard Law School. 
not just to interventions involving sophisticated technology, but to all interventions that give rise to risks of serious harm if a small mistake is made. We could not test the alternative hypotheses, but the data are not obviously inconsistent with them.

\section{E. Professional Discipline}

If the disciplinary process seeks actively to correct the problems brought about through medical malpractice, then an increase in adverse outcomes that leads to increased disciplinary action may result in an eventual reduction in the probability of an adverse outcome. However, the disciplinary process may sanction rather different behavior than that which is dealt with by the tort system. For example, in the ten years between 1969 and 1978, only 3,623 disciplinary actions were launched by American state medical boards, an average of only 362 each year. ${ }^{24}$ Weiler reports that even after marked increases in disciplinary actions in the United States over the past decade or so, by the mid-1980's there were only about 1,000 instances of probation, supervision and license revocation per year across the entire country-around 400 losses of license in a physician population of about 400,000 , compared to about 35,000 paid malpractice claims a year and a much larger number of negligently caused medical injuries which are not litigated for one reason or another. ${ }^{25}$ Moreover, most serious disciplinary actions related to behavior such as improper drug prescriptions, alcohol or drug abuse, or sexual misconduct with patients, rather than to substandard practice. ${ }^{26}$ Sloan and his colleagues also found, in examining a large Florida malpractice data base, that none of the physicians with the most adverse claims experience had their licenses suspended or revoked, and fewer than 10 percent of these physicians were disciplined in any manner. ${ }^{27}$ Therefore we expected to find that the frequency of malpractice claims is invariant to formal disciplinary proceedings by the provincial colleges of physicians and surgeons in Canada.

Relatively little information has previously been available on the interface between the tort system and the disciplinary activities of Canadian provincial colleges of physicians and surgeons. However, all provincial colleges provided us with information that yields some clues as to this interaction. The responding bodies indicated that it was extremely rare for a civil lawsuit to give rise to an investigation, and most said it never happened. Sources of information used to initiate investigations included patients, relatives and friends, other physicians, hospitals, and a mix of minor sources. The Deputy Registrar of the College of Physicians and Surgeons of Ontario stated that:

Virtually no information relating to disciplinary action comes from malpractice awards or settlements. The ultimate resolution of these civil matters occurs many. years after the facts upon which the case was based, and the College is literally the last to know.

24. Robert C. Derbyshire, How Effective is Medical Self-Regulation?, 7 L \& Human Behavior 193, 197 (1983).

25. Weiler, Medical Malpractice on Trial at 108 (cited in note 16).

26. Id.

27. Sloan, et al, $262 \mathrm{~J}$ Am Med Ass'n at 3297 (cited in note 18). 
There is no requirement on members to notify the College of civil actions taken against them. ${ }^{28}$

The disciplinary bodies of provincial colleges of physicians and surgeons appear to devote a substantial part of their resources to investigating and adjudicating allegations unrelated to negligence or incompetence. Data from the provincial colleges for 1983-1987 indicate that 69.8 percent of Canadian disciplinary cases which result in sanctions involve allegations other than negligence or incompetence, while 22.9 percent involve negligence and 7.3 percent involve incompetence. Thus, existing disciplinary mechanisms appear to have very limited overlap with the tort system.

Moreover, the number of physicians who are disciplined for negligence or for incompetence seems to be quite low compared with the number of settlements and awards for medical malpractice. As Table 6 indicates, the total number of physicians disciplined in Canada during 1983-1987 for

TABLE 6

\section{Aggregate Canadian Discipline of Negligent or Incompetent Physisians, 1983-1987}

British Columbia, 1983-1987

Alberta, 1982, 1984-1986

Saskatchewan, 1983-1987

Manitoba, 1985-1988

Ontario, 1983-1987

Quebec, ${ }^{c} 1983 / 84-1986 / 87$

New Brunswick, 1983-1987

Nova Scotia, 1986-1987

Prince Edward Island, 1983-1987

Newfoundland, 1983-1987

\begin{tabular}{ccc}
\multicolumn{2}{c}{ Physicians Formally Sanctioned For } \\
All Reasons & Negligence & Incompetence \\
60 & 0 & 4 \\
27 & 3 & 1 \\
25 & 4 & $11^{\mathrm{a}}$ \\
6 & 1 & $1^{\mathrm{b}}$ \\
105 & 64 & 5 \\
56 & $\mathrm{NA}$ & $\mathrm{NA}$ \\
35 & 3 & 1 \\
2 & 0 & 0 \\
0 & 0 & 0 \\
15 & 0 & 1 \\
328 & $75^{\mathrm{d}}$ & $24^{\mathrm{d}}$ \\
\hline
\end{tabular}

September 1981 to January 1988. Two other physicians, who refused to attend competency hearings, also might have been found incompetent.

b The same physician appears in both the "negligence" and the "incompetence" columns.

"The total number of physicians sanctioned for all causes in Quebec during the four year period 1983/84-1986/87 was 56. Extrapolated to the five year period 1983-1987, the total would be 70 . Because this total includes sanctions for reasons other than negligence or incompetence, 70 is estimated as the maximum possible number of physicians sanctioned for negligence or incompetence.

d This amount understates the Canadian total by a small amount because of missing data for a few provinces in a few years.

Source: Dewees, Coyte and Trebilcock, Canadian Medical Malpractice Liability at ch 7, Table 6 (cited in note 8 ).

negligence and/or incompetence was between 98 and 168 . The actual number likely was closer to the former than to the latter. During 1983-1987, plaintiffs received payments in respect of 916 malpractice lawsuits against CMPA-defended physicians (840 out-of-court settlements, plus 76 awards at

28. Private communication with Dr. John D. Carlisle, Deputy Registrar, The Ontario College of Physicians and Surgeons (July 15, 1988). 
trial). Thus, relative to the number of physicians in respect of whom payments were made to malpractice plaintiffs, the number of physicians formally sanctioned for negligence or for incompetence appears to be between 10.7 percent and 19.0 percent (but is likely closer to the former). Of course many patients who suffer iatrogenic injury from a physician's negligence do not undertake legal action. Danzon, on the basis of 1974 California data, estimated that at most only one malpractice claim actually was filed for every 10 incidents from which valid claims could arise. ${ }^{29}$ A recent Harvard Medical Practice Study of New York hospitals found that eight times as many patients suffered an injury from negligence as filed a malpractice claim and about sixteen times as many patients suffered an injury from negligence as received compensation from the tort system. ${ }^{30}$ Hence, if some form of no-fault compensation system supplanted tort law in this area, existing disciplinary mechanisms-if operating as they currently appear to do-would fail substantially to fill whatever deterrence role tort law might otherwise play.

Yet it would be unfair to criticize the disciplinary bodies on this basis, since they are not at present mandated to function as a shadow tort system. Indeed, as we reported above, the large malpractice claims data reveal very little evidence of recidivism-recurrent or chronic defaults in performance-which might be thought to warrant the traditional disciplinary sanctions of suspension or revocation of license, although it might be argued that the postentry quality control mechanisms of the self-governing bodies of the medical profession should be much more broadly conceived, for example, practice guidelines, practice audits, practice limits, remedial retraining.

We find that the disciplinary system deals with issues other than malpractice or incompetence; little information is passed from the tort system to the disciplinary bodies, and disciplinary action is far less frequent than successful malpractice litigation. We conclude that as it has functioned to date the disciplinary system does not significantly control malpractice and therefore is complementary to the tort system, not a substitute for it.

\section{$\mathrm{V}$ \\ The Social Environment}

Changes in the social environment are hypothesized to have lead to an increase in both the frequency and severity of malpractice litigation in Canada. These changes consist of an increase in the general propensity to litigate, changes in the specific propensity to litigate; and demographic shifts.

29. Danzon. Medical Malpractice at 29 (cited in note 10).

30. Harvard Medical Practice Study, Patients, Doctors, and Lauyers: Medical Injury. Malpractice Litigation, and Patient Compensation in .Veu York 6 (Harvard U Press, 1990). 


\section{A. General Propensity to Litigate}

Recent social and political theorizing has speculated that many citizens in Canada, the United States, the United Kingdom, and probably other industrial societies, exhibit an increasing reluctance to accept certain kinds of risks. ${ }^{31}$ To support their hypotheses these theorists often refer to the postwar growth of the welfare state, to a sharply increased role of governments in regulating health, safety, and environmental matters dating back to the 1960 's, and in the case of the tort system, to attempts to shift risks to professional service providers (or in the product liability context, to manufacturers) who are assumed to possess the necessary technical expertise to reduce or eliminate risk or, because of greater resources, to bear residual risks. In the latter case, increasing social distance between clients and professionals may encourage this attitude and heighten claims consciousness. Additionally, heightened claims consciousness may be reinforced by rising levels of higher education in the post-war decades and consequent levels of knowledge of legal rights. If this hypothesis is true, an increase in medical malpractice claims should mirror similar increases in claims in other areas. In our study, we test this hypothesis by comparing litigation trends within other self-governing professions (lawyers, architects, accountants and engineers) and within other personal injury claims (dentistry and automobile accidents).

U.S. studies reveal that the proportion of injured victims who sue for malpractice is a crucial determinant of claims frequency. Mills employed a team of medical/legal experts to review over 20,000 inpatient charts from 23 California hospitals for 1974 and found that about 1 in 20 hospital inpatients suffered an injury and 1 in 125 had a prima facie legal claim of malpractice. ${ }^{32}$ Danzon subsequently estimated that no more than one malpractice claim was filed for every 10 potentially valid claims and no more than 1 in 25 patients with potentially valid claims received any compensation. ${ }^{33}$ The rate of claims filings in the United States has roughly doubled since the mid-1970's, so one might conjecture that currently one in five inpatients with potentially valid claims may file suit, although the Harvard Medical Practice Study of New York hospitals (discussed above) concluded that the ration was one in eight. If negligent injuries were equally common in Canada, then the far lower Canadian frequency would imply that about one in twenty-five patients with a valid claim may file suit here. Clearly there is considerable scope for changes in the frequency of litigation arising out of changes in the propensity to sue once an injury has occurred.

We compared trends in rates of frequency of claims against physicians with trends in frequency of claims rates in other litigation contexts. We found that

31. Yair Akaroni, The No-Risk Society (Chatham House, 1981); Mary Douglas \& Aaron B. Wildavsky, Risk and Culture (U Cal Press, 1982): Daniel Polisar \& Aaron B. Wildavsky, From Individual to System Blame: A Culiural Analysis of Historical Changes in the Law of Torts, 1 J Pol'y History 129,130 (1989).

32. Don Harper Mills, Medical Insurance Feasibility Study-A Technical Summary, 128 W J Med 360 (1978).

33. Danzon, Medical Malpractice at 24 (cited in note 10). 
over the past decade there have been marked increases in frequency rates for non-Ontario lawyers, for Ontario dentists, (see Table 7) and somewhat less dramatic increases in third-party bodily injury claims arising out of automobile accidents in Ontario and the Atlantic provinces (not shown). On the other hand, claims rates for Canadian architects, engineers and chartered accountants and for Ontario lawyers do not reflect any such increases. However, if we consider trends in the United Kingdom, architects, accountants, and veterinary surgeons experienced sharp increases in frequency rates. In the case of architects, there was one claim for every seven policies in 1979 and seven for every ten in 1987. Claims against veterinary surgeons in Britain doubled between 1981 and 1987, and the real value of paid and reserved claims against accountants increased by 82 percent between 1979 and 1984.34

To the extent that these comparative data suggest an increase across nations in the general propensity to sue professionals, they may provide support for the hypothesis of an attitudinal shift towards risk-bearing in some contexts. Increasing social distance between clients and professionals may also encourage greater resort to the tort system and heightened claims consciousness. However, our data revealed no significant positive relationship between interprovincial migration and immigration per capita and the frequency of malpractice litigation, although the higher frequency rates with respect to physicians practicing in urban centers and with respect to hospitals located in urban centers might be interpreted as providing support for the social distance hypothesis. Efforts to rationalize hospital services in Canada over recent years by reducing the role of small community hospitals and expanding the role of large regional hospitals may have reinforced these trends.

\section{B. Specific Propensity to Litigate}

One factor that may distinguish willingness to bear risk from medical procedures from willingness to bear other risks is the rising expectations of the medical sector. Over the last several decades the public has repeatedly been presented with news of major advances in medicine, which may have led the public to exaggerate the ability of the medical profession to cure their ills and redress their injuries. If this is true, then bad outcomes of medical treatment will increasingly be treated as failures, and perhaps the result of the incompetence of the physician. Patients who in the past might have accepted their condition now believe that their condition is an aberration, and demand compensation. Although we were unable to obtain data on public attitudes towards the medical profession, we feel that these attitudes may be an important factor. The significance of the lagged dependent variables in our statistical analysis indicates that there is inertia in the causation of these

34. Chris Ham, et al, Medical Negligence: Compensation and Accountability 15 (King's Fund Inst, 1988). 
TABLE 7

Claims Experience of Non-Health Professions

INCIDENT-YEAR BASIS

Varied Growth in Relative Claims

FREQUENCY $1982=100$

\begin{tabular}{lccccc} 
Year & $\begin{array}{c}\text { Ontario } \\
\text { Lawyers }\end{array}$ & $\begin{array}{c}\text { Non-Ontario } \\
\text { Laywers }\end{array}$ & $\begin{array}{c}\text { Canadian } \\
\text { Chart. Accts. }\end{array}$ & $\begin{array}{c}\text { Canadian } \\
\text { Arch \& Eng }\end{array}$ & $\begin{array}{c}\text { Ontario } \\
\text { Dentists }\end{array}$ \\
1976 & N.A. & 38.3 & N.A. & 102.9 & 53.6 \\
1977 & 71.5 & 31.0 & N.A. & 90.5 & 60.1 \\
1978 & 115.5 & 45.8 & N.A. & 105.6 & 74.3 \\
1979 & 123.4 & 56.0 & N.A. & 120.1 & 83.5 \\
1980 & 147.0 & 53.3 & 144.8 & 109.0 & 72.0 \\
1981 & 134.1 & 58.5 & 76.6 & 112.4 & 93.9 \\
1982 & 100.0 & 100.0 & 100.0 & 100.0 & 100.0 \\
1983 & 104.5 & 75.4 & 116.5 & 95.7 & 91.4 \\
1984 & 122.9 & 99.5 & 116.1 & 79.3 & 191.7 \\
1985 & 112.1 & 103.3 & 95.2 & 56.0 & 145.9 \\
1986 & 106.7 & 66.4 & 98.0 & 58.1 & 168.6 \\
1987 & 115.0 & N.A. & 81.7 & 71.9 & 190.8 \\
\hline
\end{tabular}

[Numbers in recent years understate frequency rates because of unreported claims.]

\section{Modest Growth in Relative Severity $1982=100$}

\begin{tabular}{lccccc} 
Year & $\begin{array}{c}\text { Ontario } \\
\text { Lawyers }\end{array}$ & $\begin{array}{c}\text { Non-Ontario } \\
\text { Lawyers }\end{array}$ & $\begin{array}{c}\text { Canadian } \\
\text { Chart. Accts. }\end{array}$ & $\begin{array}{c}\text { Canadian } \\
\text { Arch \& Eng }\end{array}$ & $\begin{array}{r}\text { Ontario } \\
\text { Dentists }\end{array}$ \\
1976 & N.A. & 45.3 & 374.6 & 97.6 & 97.8 \\
1977 & 82.1 & 45.1 & 122.4 & 129.7 & 385.8 \\
1978 & 88.6 & 57.5 & 142.8 & 103.6 & 69.5 \\
1979 & 78.4 & 82.8 & 48.7 & 105.4 & 83.6 \\
1980 & 71.5 & 95.2 & 154.6 & 97.9 & 120.4 \\
1981 & 111.6 & 92.6 & 184.1 & 118.3 & 102.4 \\
1982 & 100.0 & 100.0 & 100.0 & 100.0 & 100.0 \\
1983 & 137.9 & 66.8 & 107.0 & 91.0 & 118.2 \\
1984 & 125.2 & 75.6 & 61.3 & 83.2 & 65.7 \\
1985 & 142.1 & 43.9 & 60.3 & 98.6 & 62.0 \\
1986 & 161.2 & 44.6 & 42.0 & 102.4 & 76.4 \\
1987 & 176.6 & N.A. & 46.2 & 90.4 & 97.0 \\
\hline
\end{tabular}

[Numbers in recent years may understate severity rates because of underreporting of more serious claims.]

Source: Dewees, Coyte and Trebilcock, Canadian Medical Malpractice Liability at ch 6 (cited in note 8 ).

changes, which could represent changes in social attitudes toward suing physicians.

\section{Demographic Shifts}

Another way to identify sources of increased claims is to try to identify population groups that are significantly at risk of costly injuries. One might hypothesize that the risks of childbirth would cause women of child-bearing age to be over-represented in the patient population, and similarly that 
newborns would be over-represented. One might also expect high representation from the elderly, given their reduced ability to recover from trauma, but this could be offset by lower damage awards for those who have lost fewer years of earning power, and whose cost of care will be limited by a limited natural lifespan.

We performed a regression analysis of the semi-aggregate Canadian claims data, defining these high-risk groups as: children under five years old; women aged eighteen to forty-four; and patients over sixty-five. We found that although the demographic variables were unrelated to both the frequency of malpractice claims and the proportion of paid claims, they were all significant in determining the size of the average paid claim. Specifically, an increase in either the proportion of the population under five or women aged eighteen to forty-four raises the average paid claim, while an increase in the proportion of the population over sixty-five lowers the average paid claim.

Although the results derived from the inclusion of the demographic variables are consistent with the foregone earnings hypothesis, an explicit test of this hypotheses requires the inclusion of a variable representing the patient's real wages at the time the malpractice case was closed. Since the median interval between the incident date and the date at which the case closed is just over three years, we used average real wages three years after the incident date to test these hypotheses. Wages were found to be significantly positively associated with the average paid claim, but unrelated to the other dimensions of malpractice liability. ${ }^{35}$

In addition to forgone earnings, the nominal rate of inflation should be positively associated with the average paid claim because pre-judgment interest is added to the calculated damages. The large claims data revealed an increase in "interest" elements in claim payments from 4 percent in early claims to 7 percent in later claims. To test this hypothesis, we included the yield on long term bonds (ten years and above) lagged three years from the accident year to approximate the time that the case closed. The results show a significant positive relationship between the yield on long term bonds and the average paid claim, thereby supporting the hypothesis that pre-judgment interest is an important determinant of the severity of malpractice claims. ${ }^{36}$

We explored a more limited set of demographic issues by examining the age distribution of patients in the large claim data set. The special risks arising from childbirth are demonstrated in the 10 patients, representing 9 percent of all patients, in the youngest category, all of whom were injured at or before birth. Of these newborns, 9 were male and only one was female. The age distribution of injured females includes large numbers in their 20's and 40's, while the males are predominantly in their 20's and 30's. Fully 64 percent of the patients are males, belying the hypothesis that females would predominate because of the risks associated with childbirth. Contrary to one

35. Dewees, Coyte \& Trebilcock, Canadian Medical Malpractice Liability at 4-34 (cited in note 8).

36. Id at $\mathbf{4 - 3 5}$. 
hypothesis, the elderly are rare as plaintiffs in large claims, perhaps reflecting the relatively smaller damages that would be awarded based on lost earnings for a given injury to an elderly person in comparison to the damages for the same injury to a young person. Because we do not have data on the age distribution of medical patients in general, we cannot draw strong conclusions from these results, but of our three expected high risk groups, only infants stand out in these data.

Claims for injuries to infants included a disproportionate number of males: nine males, one female. This is unlikely to represent random variation in the data, since the likelihood of finding only one female among ten injured is one in 100 if the injuries are actually equally distributed. However, an important element in damages is lost earnings, and even today most courts are likely to assess substantially higher lost earnings for a male than for a female. Higher expected damages for males could lead to a greater propensity to sue for an injured male newborn. Thus, this disproportionate number of male infant plaintiffs, and the general excess of males over females, may reflect greater lost earnings for males, which in turn causes an increase in the frequency with which injuries are litigated. If so, it is an example of increased severity driving increased frequency.

\section{VI \\ The Legal Environment}

There are three major categories of changes within the legal environment that may explain the increase in malpractice litigation frequency and severity in Canada: liability rules, compensation rules; and legal costs.

\section{A. Liability Rules}

Over the last twenty years in many jurisdictions, there has been, for example, a relaxation in both the customary practice and locality rules, an enlargement of the scope of the doctrine of res ipsa loquitur, enlarged scope for jury determination, erosion of the technical expertise/common knowledge distinction in defining standards of care. Many of these changes, might be expected to increase the frequency of malpractice claims. They are, however, difficult to measure.

Studies in the United States have revealed that changes in some doctrines do affect malpractice litigation. Danzon has shown that pro-plaintiff laws (covering the abolition of the locality rule and charitable immunity, more stringent requirements of informed consent, and respondeat superior) contributed significantly to the growth in both the frequency and severity of malpractice claims. ${ }^{37}$ Although similar conclusions were reached by Reder

37. Danzon, 27 J L \& Econ at 137 (cited in note 10). 
and Feldman, ${ }^{38}$ Sloan found no effect or perverse effects of legislative changes on premiums. ${ }^{39}$ Adams and Zuckerman found the frequency of malpractice claims to be positively associated with both more generous limitations periods and with restrictions on the doctrine of informed consent. ${ }^{40}$ While initially Danzon was unable to observe any significant effect of shorter statutes of limitations, ${ }^{41}$ in a more recent study she found that on average cutting one year off the statute of limitations for adults reduces claims frequency by eight percent. ${ }^{42}$

Our regression analysis on the Canadian data reveals that both the severity of injuries and the proportion of paid claims responded slowly to changes in explanatory variables which may capture the slow evolution of legal doctrines and/or changes in social attitudes towards malpractice litigation. This result provides support for the view that considerable inertia exists in the determination of both the proportion of paid claims and in the severity of these claims.

We expect that increases in the predicted proportion of claims paid will increase the frequency of malpractice claims on the grounds that the litigant has a greater incentive to file a malpractice claim if he anticipates a higher probability of a successful suit. Our regression analysis found a significantly positive relationship between the predicted proportion of claims paid and the frequency of malpractice claims, supporting the hypothesis that liability rules play a significant role in the initiation of malpractice litigation. Indeed, after accounting for the contribution of both surgical procedures and the predicted size of the paid claim on the frequency of malpractice claims, the predicted proportion of claims paid is the next most important variable accounting for variations in the frequency of malpractice litigation.

Two legal changes that are easier to measure and quantify are the more stringent requirements for informed consent, which were imposed by a 1980 Supreme Court of Canada decision, ${ }^{43}$ and more generous limitations periods. In our study, we focus mainly on the former, since the changes in limitation periods in Canada occurred in different provinces at different times, and could not be captured in our nationally aggregated data.

We tested the impact of more stringent requirements for informed consent on the three dimensions of malpractice liability: frequency of claims filing, proportion of claims paid, and magnitude of the award (severity). Our informed consent variable distinguishes claims settled before and after January 1, 1981, the approximate date that informed consent requirements

38. Melvin W. Reder, An Economic Analysis of Malpractice, 5 J Legal Stud 267, 287 (1976); Roger Feldman, Determinants of Medical Malpractice Incidents: Theory of Contingency Fees and Empirical Evidence, 7 Atlantic Econ J 59 (July 1979).

39. Sloan, $9 \mathrm{~J}$ Health Pol, Pol'y \& $\mathrm{L}$ at 639 (cited in note 10).

40. Adams \& Zuckerman, $9 \mathrm{~J}$ Health, Pol, Pol'y \& $\mathrm{L}$ at 485 (cited in note 20).

41. Danzon, $27 \mathrm{~J} \mathrm{~L} \mathrm{\&} \mathrm{Econ} \mathrm{at} 139$ (cited in note 10).

42. Danzon, 49 L \& Contemp Probs at 71-72 (cited in note 9); see also Zuckerman, Bovbjerg \& Sloan, 27 Inquiry at 180 (cited note 9).

43. Reibl y Hughes, 2 SCR 880, 114 DLR3d 1 (S Ct Canada 1980). 
were changed. Other events at about the same time are also captured by this variable. The move to apply real discount rates to future costs, which increased awards with large future cost components, occurred about 1980 in Ontario. The inclusion of gross-up for taxes on awards occurred in Ontario during the early 1980's. Although the informed consent variable has an insignificant negative effect on both the proportion of paid claims and the severity of those claims, it is significantly positively related to the frequency of claims filing, indicating that this legal change has significantly increased the claims frequency.

\section{B. Compensation Rules}

Changes in legal doctrine that increase the damages awarded for a given injury should increase the average size of an award and the frequency of claims filed. Previous studies in the United States have explored these relationships.

Danzon has examined the impact on malpractice litigation of various doctrinal changes relating to quantum of damages. ${ }^{44}$ With respect to changes in compensation rules, she found that the introduction of laws that allow or require reductions in awards to reflect coverage from other sources (collateral benefits) reduce significantly both the frequency and severity of malpractice claims-frequency by fourteen percent and severity by eleven to eighteen percent relative to comparable states without collateral source offset. ${ }^{45}$ Danzon alone, and Danzon and Lillard also found that caps on awards have reduced the severity of malpractice claims by about twenty-three percent on average. 46 Consequently, we anticipated finding a positive relationship between both the frequency and severity of malpractice claims in Canada and our estimates of the damages awarded to successful litigants.

Doctrinal changes, such as changes in the assessment of non-pecuniary damages, pre-judgement interest, the use of real interest rates to discount future losses to present value, gross-up, and allowing relatives' claims under Ontario's Family Law Reform Act, increase the quantum of damages and raise the value of both settlements and court awards. This should increase the frequency of claims filing. Although the rules governing compensation have evolved slowly over the past twenty years, three landmark cases, the 1978 "trilogy" of decisions by the Supreme Court of Canada, ${ }^{47}$ laid out the general

44. Danzon, $27 \mathrm{~J}$ L \& Econ at 138-39 (cited in note 10); Danzon, Medical Malpractice at 158-73 (cited in note 10); Danzon, $49 \mathrm{~L}$ \& Contemp Probs at 76-78 (cited in note 9). See also James W. Hughes, The Effect of Medical Malpractice Reform Laws on Claim Disposition, 9 Int'l Rev L \& Econ 57 (1989).

45. Danzon, $27 \mathrm{~J} \mathrm{~L} \&$ Econ at 138-42 (cited in note 10); Danzon, 49 L \& Contemp Probs at 71 72 (cited in note 9 ).

46. Id; Patricia M. Danzon \& Lee A. Lillard, Settlement Out of Court: The Disposition of Medical Malpractice Claims, $12 \mathrm{~J}$ Legal Stud 345, 372-74 (1983). See also Sloan, Mergenhagen \& Bovbjerg, 14 $\mathrm{J}$ Health Pol, Pol'y \& $\mathrm{L}$ at 678 (cited in note 10).

47. Andrews v. Grand and Toy Alberta Ltd., 2 SCR 229, 83 DLR3d 452 (S Ct Canada 1978); Thornton v. School Dist. No. 57 (Prince George), 2 SCR 267, 83 DLR3d 480 (S Ct Canada 1978); Amold v. Teno, 2 SCR 287, 83 DLR3d 609 (S Ct Canada 1978). 
principles of damage calculation in personal injury cases. In our study, we focus particularly on the implications for frequency and severity of malpractice claims of the grossing-up of damage awards to offset the tax impact on the income stream from invested awards. The income tax gross-up was recognized by Ontario courts immediately following the "trilogy" and according to $\mathrm{Rea}^{48}$ has substantially increased the quantum of damages in serious personal injury cases.

The semi-aggregate Canadian claims data allow only limited testing of hypotheses relating to compensation rules. An injured patient should have a greater incentive to initiate a malpractice claim when the predicted award for the malpractice claim increases. The finding in the regression analysis that the frequency of claims is significantly positively related to the predicted severity of such claims provides support for the hypothesis that compensation rules play a significant role in the initiation of malpractice litigation. The predicted severity variable is the second most important variable accounting for variations in malpractice litigation after the utilization of major surgery.

By moving from a model of malpractice claims frequency that rests solely on surgical utilization to a model that also depends on the predicted severity of settlements, the predicted proportion of successful claims, and restrictions on the defence of informed consent, we increase the proportion of the variability in the frequency of claims filing that we can explain from 90 to almost 95 percent. This means that the addition of the legal variables to the frequency equation allows us to account for 50 percent of the variation in the frequency of malpractice claims over time and 98 percent of the interspecialty variation in the 1976-84 data set. However, we are not convinced that these statistical results imply that changes in legal doctrine, including both liability rules and compensation rules, account for one-half of the almost quadrupling in frequency of suits filed per practicing physician between 1971 and 1988. The statistical analysis covers only one-half of the total time period of interest. Furthermore, there was little change in legal doctrine during the 1970's when one-half of the growth in frequency occurred. We suspect that changes in legal doctrine actually account for closer to one-third than one-half of the increase in frequency of litigation over the entire period.

The large claims data allow for more detailed analysis of the compensation rules, since they include the total amount awarded for each claim, and a breakdown of the award into the following components: lost income, medical expenses, past medical expenses, cost of care, initial outlay and past cost of care, gross-up, claims by relatives, interest, legal costs, other expenses, and nonpecuniary damages.

The relative importance of the components of damages is shown in Table 8. After some adjusting, the sum of the components of the CMPA share of payments is 64.5 million 1990 U.S. dollars. Approximately 27 percent of this

48. Samuel A. Rea, Jr., Economic Perspectives on the Liability Insurance Crisis, in Law Society of Upper Canada, ed, Insurance Law 1, 8 (DeBoo, 1987) ("Economic Perspectives"). 
amount is attributed to lost income, 36 percent to a category including medical expenses, cost of care, initial costs, and gross-up. Nonpecuniary damages accounted for $\mathbf{1 5 . 4}$ percent of the total (dramatically lower than in the United States). Other elements are also shown in the table.

TABLE 8

Components of Damages in LaRge Claims (Millions of 1990 US \$)

\begin{tabular}{lcrrrr} 
& All Claims & \multicolumn{2}{c}{ Early } & \multicolumn{2}{c}{ Late } \\
& & \multicolumn{1}{c}{$\$$} & \multicolumn{1}{c}{$\%$} & \multicolumn{1}{c}{$\%$} \\
Lost Income & 17.6 & 7.9 & 26.4 & 9.7 & 27.9 \\
Care Cost* & 23.4 & 11.6 & 38.8 & 11.9 & 34.2 \\
Awards to Relatives & 5.5 & 2.3 & 7.7 & 3.2 & 9.2 \\
Interest & 3.6 & 1.2 & 4.0 & 2.5 & 7.2 \\
Legal Cost & 3.4 & 1.4 & 4.7 & 2.0 & 5.7 \\
Non-Pecuniary & 9.6 & 5.0 & 16.7 & 4.6 & 13.2 \\
Other & 1.4 & 0.5 & 1.7 & 0.9 & 2.6 \\
Total & 64.5 & 29.9 & & 34.8 & \\
\hline
\end{tabular}

* "Care Cost" includes medical and post-medical expenses.

Source: Dewees, Coyte \& Trebilcock, Canadian Medical Malpractice Liability at Table 4-26 (cited in note 8 ).

We note that Rea predicted that awards for short term partial disability could increase by 2 percent per year due to the effect of the "trilogy" cases on damage calculations, and that awards for permanent disability of a 21-year old might increase by as much as 16 percent per year (in real terms). ${ }^{49} \mathrm{We}$ therefore expected large increases in the magnitude of awards attributable to gross-up, to the use of lower real interest rates for discounting future earnings loss and cost of care, and increases in the early 1980's attributable to the awarding of pre-judgment interest.

To investigate whether there has been a change over time in the allocation of these damages, we divided the claims into those closed prior to January 1 , 1985 ( 50 claims) and those closed after that date $(57$ claims). The distribution of payments among the components of damages for these "early" and "late" claims is also shown in Table 8 .

Although we predicted that the allowance of gross-up in Ontario after January 1, 1980 and other factors would have led to an increase in the relative importance of care costs between the early and late claims in fact they decline in relative importance. ${ }^{50}$ An examination of the amounts allocated specifically for gross-up shows that this allocation occurred only in Ontario, but that it accounted for a total of only $\$ 454,000$ representing a small handful of claims, an amount too small to account for significant upward trends in liability. We are confident that gross-up has added much more than this to the amounts awarded in malpractice cases involving permanent disability, so we must

49. Id at 12

50. Only a small number of claims is included in the "early" data, so this test is not robust. 
conclude that the large claims data have failed to identify separately this head of damages in many cases.

Ontario claims represented 53.6 percent of the total care costs, compared to 51 percent of total claims dollars paid, which only weakly supports the hypothesis that gross-up costs, included in these total care costs, in Ontario are significantly greater than in other provinces. On the other hand, payments for Ontario claims increased more rapidly than those of the other provinces during the 1980 's, so gross-up may have contributed to this increase.

During the 1970s, most provinces began to allow compensation for prejudgement interest. Ontario allowed pre-judgement interest in 1977 . Unfortunately, most of these changes took place before the closing date of most of the large claims, so we cannot test accurately whether there was a change in the amount of pre-judgement interest awarded. Table 8 , however, shows clearly that interest payments rose from 4.0 percent in the early claims to 7.2 percent in the later claims. Since nominal interest rates increased greatly during the early 1980s, the increase in interest costs shown in Table 8 may be primarily attributable to increasing interest rates, rather than to changes in the allowance of pre-judgment interest.

A third legal doctrine involves increased entitlements for third-party claims by relatives. Again, different provinces allowed this recovery at different times. Ontario expanded its compensation in this area with the Family Law Reform Act of 1978. Table 8 shows claims by relatives increasing from 7.7 percent of the total payments in the early period to 9.2 percent in the later period. This appears consistent with the expansion of the doctrine allowing such claims. Here, Ontario claims represent 70 percent of all awards for claims by relatives, indicating that such claims are relatively much more important in Ontario than in the other provinces. Since total payments to relatives amounts to about $\$ 5.5$ million in the large claims data, the extra cost of Ontario's expanded liability is significant.

We also tested whether increasing legal fees could be a factor in increasing malpractice payments. Legal fees rose from 4.7 to 5.7 percent of the total payments between the early and the late period. Here, again, Ontario's share of legal costs exceeds its share of all costs, so Ontario plays a prominent role in this increase. However the total amounts are not large enough to contribute greatly to the overall growth in loss experience.

We also used the large claims data set to examine whether the cost of a given type of claim has increased between the late 1970's and the mid-1980's, by selecting from the large claims those that seem similar in both the early and late part of the period and comparing their magnitude. Four sets of cases were examined.

First, we examined the claims for serious injuries to newborns. Rea ${ }^{51}$ predicts that settlements for permanent total disability of young patients

51. Rea, Economic Perspectives at 12 (cited in note 48). 
should rise dramatically in real terms (after account for inflation) between about 1978 and 1983. The data for 10 such claims in our large data set do seem to show a doubling of claim size between 1980 and 1983, but a drop in 1986 is inconsistent with the hypothesis. However, liability was not admitted in one of the 1986 claims, which may have led to a settlement lower than would have been achieved if liability were admitted (as it apparently was in all other cases). If the no-liability claim is omitted, the 1986 average is consistent with the hypothesis that there was a marked increase from 1980 to 1983.

Our second approach was to examine claims involving fatalities. The average magnitude of these claims was just over $\$ 411,000$. Here we found three males within the ages of 30 to 33 years whose claims were settled before the end of 1980 , with an average settlement of $\$ 286,000$. Four males aged 27 to 38 years were found whose claims were settled between 1982 and 1987 . One of this group suffered almost $\$ 1$ million in lost income, an extraordinarily high value in this data set. Setting aside that individual, we have three late fatalities for an average claim of $\$ 377,000$. These data imply an increase in compensation for a fatality of approximately one-third between about 1979 and about 1983 .

Third, we examined claims involving grave permanent disability excluding newborns. When we examined matched sets of males or females in similar age ranges, divided into the early and late period, no support could be found for the hypothesis that damage awards had increased. In fact, reductions of approximately one-quarter to one-third were observed in the three sets of matched data that were discovered. It seems likely that this result must arise from important differences between the matched pairs of data, but we have not been able to investigate this further.

Finally, we examined the claims of person who experienced major permanent and total disability. ${ }^{52}$ Three matched pairs of cases, one male and two female, all in their mid-teens to mid-twenties were identified. In each of these cases, there was a considerable increase in the damages awarded ranging from 33 percent to 500 percent. We conclude from these data that with respect to this type of injury average compensation has indeed increased-by 50 percent to 100 percent-from the late 1970's to the mid1980's.

The large claims data do not yield unambiguous support for the proposition that average severity has increased. However there is strong evidence in the case of persons' permanently and totally disabled that very considerable increases in damages have occurred. There may also have been a large increase in compensation for disabling injuries to newborns during the early 1980's.

52. "Major permanent total disability" differs from "grave permanent disability" mentioned above in that the latter describes disability which, while serious and permanent, does not prevent the person from carrying on some meaningful work or the activities of daily life, although it interferes in an important way with that work or activity. The former term describes disability that precludes all such work and activity. 


\section{Legal Costs}

A decline in legal costs may increase the frequency with which malpractice claims are filed since the plaintiff incurs a lower cost in the event of an unsuccessful suit. Specifically, the availability of both legal aid and contingency fees ${ }^{53}$ in malpractice cases may have a significant effect. In addition, some commentators argue that an increased supply of lawyers lowers prices for legal services, thereby making litigation more attractive for the plaintiff. ${ }^{54}$ Although there is considerable appeal to the hypothesis that both the frequency and the severity of malpractice claims are influenced by the supply of lawyers, the existing empirical results from the United States do not support this hypothesis. ${ }^{55}$ In spite of finding a positive association between lawyers per capita and the frequency of malpractice claims, Danzon is able to reject this hypothesis when she corrects for other characteristics of those areas with a high lawyer density. We were not able to test for the effects of legal aid and contingency fees on the frequency of malpractice claims (the CMPA claims data do not reveal which cases were financed in these ways), but we did test the relationship between the supply of lawyers and the trends in malpractice claims.

We performed an analysis of the impact of the supply of lawyers on the frequency of litigation, using the semi-aggregate data. Although a decline in legal costs may increase the frequency of malpractice litigation, we were unable to observe the legal costs associated with a malpractice claim directly in the semi-aggregate data. We were, however, able to approximate the movement in legal costs by considering the state of the market for lawyers. Specifically, we examined the effect of an increase in the number of lawyers per capita, excluding lawyers in corporate law departments and notaries in all provinces including Quebec, on all three dimensions of malpractice liability: frequency, proportion of claims filed that yield compensation, and severity. The results all reveal insignificant effects of lawyers per capita on malpractice litigation, thereby rejecting the hypothesis that the trends in malpractice liability are due to an increase in the supply of lawyers. Of course, the real

53. Although Danzon \& Lillard, $12 \mathrm{~J}$ Legal Stud at 372-78 (cited in note 46), did not consider the effect of caps on contingency fees on the frequency of malpractice claims, they did find that these caps had a negative effect on the severity of such claims. Danzon failed to replicate these results, see generally Danzon, 27 J L \& Econ 115 (cited in note 10); Danzon, Medical Malpractice (cited in note 10). See also Reder, 5 J Legal Stud at 285-92 (cited in note 38); Steven Shavell, Theoretical Issues in Medical Malpractice, in Simon Rottenberg, ed, The Economics of Medical Malpractice 53 (Am Enterprise Inst, 1978).

54. Glen O. Robinson, The Medical Malpractice Crisis of the 1970's: A Retrospective, 49 L \& Contemp Probs 5, 14-15 (Spring 1986).

55. Reder, $5 \mathrm{~J}$ Legal Stud 267 (cited in note 38); Danzon, $27 \mathrm{~J} \mathrm{~L} \mathrm{\&} \mathrm{Econ} 115$ (cited in note 10); Danzon, Medical Malpractice (cited in note 10); Danzon, 49 L \& Contemp Probs 57 (cited in note 9). Notable exceptions to this observation are Feldman, 7 Atlantic Econ J 59 (cited in note 38), and Sloan, $9 \mathrm{~J}$ Health Pol, Pol'y \& L 629 (cited in note 10). Feldman found an inverse relationship between the earnings of lawyers and the frequency of malpractice claims, while Sloan found a positive relationship between lawyers per capita and malpractice premiums. Unfortunately, neither of these studies controlled for urbanization, which Danzon found to be the single most important variable explaining the variation in malpractice litigation. See Danzon, $27 \mathrm{~J} \mathrm{~L} \&$ Econ at 135 (cited in note 10 ). 
issue is not the supply of lawyers, but the cost or opportunity cost of lawyers' time, which depends on both the supply and the demand for legal services. We do not have the data necessary to perform this test, so our conclusion is a weak one: an increased supply of lawyers does not seem to cause an increase in malpractice litigation.

\section{VII}

\section{Conclusion}

First, why have malpractice claims risen so sharply in Canada?

A substantial portion of the 1971-90 increase in claims, perhaps one-third, seems attributable to changes in legal doctrines. Compensation rules were more important than liability rules, but both played a role. In some cases these doctrinal changes occurred in Canada at the same time as, or shortly after, similar changes in the United States, but some changes were unique to Canada. As to the remaining increase, we find some evidence of an increased general propensity for individuals to sue professionals. This finding tentatively confirms recent theorizing about changes in general social attitudes to some forms of risk bearing and the use of litigation to shift risks. A social/professional change, the increased willingness of doctors to testify against one other, also facilitated successful claims by injured patients. So, too, changing medical technology and practice seem to have played a major role. The overwhelming effect of differences in major surgery in explaining cross-specialty frequency rates and other more impressionistic evidence from the large claims data set, lend some credence to the Grady hypothesis. That is, rapid technological and scientific innovation, although presumably reducing health risks for society at large, sharply raises possibilities for momentary acts of inadvertence by physicians and other medical staff that affect outcomes precisely because of the increased power of medicine. Moreover, the legal system is insensitive to the cost-benefit trade-off inherent in achieving consistently high levels of advertence. The increasing intensity and complexity of medical treatment now provides more witnesses to incidents of malpractice, easing the plaintiff's problems of proof, while the improved effectiveness of medical treatments may lead victims and juries to conclude that those adverse outcomes that occur must be attributable to malpractice. Finally, widespread publicity about medical advances may have raised public expectations, increasing the propensity to sue when an outcome is unsatisfactory.

For these reasons, we believe that advancing medical technology and practice may contribute simultaneously to improved aggregate patient outcomes and to increased malpractice liability. The three countries examined herein have experienced similar growth in malpractice litigation during the 1970's and 80's. This parallelism suggests that this growth must arise less from isolated doctrinal changes in one country than from changes in medical practice and social mores, which occur roughly simultaneously in most western countries. These driving forces find different outlets in 
different countries; expansive legislation, judicial innovation, lenient jury verdicts, and more aggressive behavior of plaintiffs and their attorneys. Moreover, substantial increases in frequency and severity of malpractice claims in Canada occurred over the course of the 1970's, before any significant doctrinal changes occurred in the law. This reinforces the importance of these non-legal explanatory factors, and raises questions about "tort reform" as a response to the growth in liability, at least in Canada.

Second, our study finds no evidence that so-called defensive medicine significantly influences the frequency of claims filed, the proportion of claims that succeed, or the average magnitude of awards. Similarly, age and place of training of physicians and increases in the supply of lawyers do not seem to be significant factors in explaining malpractice litigation trends. There also appears to be little relationship between the functioning of the malpractice system and the functioning of the formal disciplinary processes of the medical profession.

Third, as to trends in severity, we found few significant differences across specialties (with the exception of higher mean awards against anesthetists). Average real severity grew substantially over time with respect to all physicians more or less alike. Hence this increase seems primarily attributable to changes in compensation rules and to a lesser extent to demographic changes and changes in medical technology, especially with respect to infants (again perhaps exemplifying the Grady hypothesis).

We conclude that policy perspectives on the so-called medical malpractice crisis-in terms of ameliorating its more dysfunctional features and of exploring alternative injury reduction and compensatory strategies-need to be much more broadly cast than the overwhelming preoccupation with tort reform issues that have dominated policy debates to this juncture. 


\section{,}

